\title{
Adherence to treatment and evaluation of disease and therapy knowledge in Lebanese hypertensive patients
}

This article was published in the following Dove Press journal:

Patient Preference and Adherence

\author{
Hanine Abbas' \\ Mazen Kurdi' \\ Myriam Watfa ${ }^{2}$ \\ Rita Karam ${ }^{1-3}$ \\ 'Department of Chemistry and \\ Biochemistry, Faculty of Science, \\ Lebanese University, ${ }^{2} \mathrm{Q}$ uality \\ Assurance of Pharmaceutical Products \\ Department, Lebanese Ministry \\ of Public Health, ${ }^{3}$ Pharmacology \\ Department, Faculty of Medical \\ Sciences, Lebanese University, \\ Beirut, Lebanon
}

Background: Adherence to treatment, healthy lifestyle, physical activities, smoking, diet, and salt intake are important factors to control for an effective decrease in blood pressure (BP) values for patients diagnosed with essential hypertension (HT). The aim of this work was to study the adherence to antihypertensive treatment and factors predicting this behavior in Lebanese patients. In addition, we evaluated the extent of patient's knowledge and perceptions about HT, risk factors, and medication side effects.

Methods: The cross-sectional study was conducted between May and September 2015 among 249 participants randomly recruited from community and hospital pharmacies (56.6\%), private cardiology clinics (37\%), and outpatient clinics located in hospitals (6.4\%) in Baabda region of Lebanon. The questionnaire was prepared after reviewing published literature. Data were collected by trained and certified interviewers and analyzed by Statistical Package for the Social Sciences program. $p$-value less than 0.05 was considered to determine the statistical significance.

Results: Among the 249 patients interviewed, $48 \%$ were females with a mean age of $62 \pm 17.2$ years. Overweight and obesity was declared in $42.2 \%$ and $35.3 \%$, respectively. Only $52.6 \%$ of participants reported visiting their physicians for regular checkups, and $72 \%$ claimed checking their BP routinely at home. Awareness of complications related to HT was very high (97\%). However, our results showed that $89.2 \%$ of the participants were found to be adherent to treatment, and forgetfulness was cited as the main reason for non-adherence to therapy. Only health coverage showed statistical significance $(p=0.01)$ between adherent and non-adherent participants.

Conclusion: A better communication between patients and their physicians, the use of a special container for medication packaging, and reminder to refill prescriptions are important parameters to enhance adherence to treatment. HT can be better managed if an educational system is implemented to increase awareness.

Keywords: Lebanon, hypertension, treatment, compliance, adherence, awareness

\section{Introduction}

High blood pressure (BP) is estimated to cause 7.5 million deaths worldwide, about $12.8 \%$ of the total deaths, and it accounts for 57 million disability-adjusted life years (DALYS), or 3.7\% of the total DALYS. ${ }^{1}$ The overall prevalence of increased BP in people 25 years or older was about $40 \%$ in $2008 .{ }^{1}$ In Lebanon, a population-based study conducted in 2005 revealed that the overall prevalence of declared hypertension (HT) was $23.1 \% .^{2}$ In a more recent study conducted in 2015 , the prevalence, awareness, treatment, and control (among treated hypertensive) rates of HT were $36.9 \%$,
Correspondence: Rita Karam

Faculty of Sciences, Section I, Lebanese University, Beirut, Lebanon Tel +96I 377506 I

Email ritakmouawad@hotmail.com 
$53 \%, 48.9 \%$, and $54.2 \%$, respectively. Overall, only $27 \%$ of patients with HT had their BP under control. ${ }^{3}$ Based on recommendations of the Joint National Committee 8 , HT is defined as systolic blood pressure (SBP) of $140 \mathrm{mmHg}$ or higher, or diastolic blood pressure (DBP) of $90 \mathrm{mmHg}$ or higher. ${ }^{4}$ The first approach in treating HT is through lifestyle modifications. A Dietary Approach to Stop Hypertension (DASH) diet is highly recommended. BP control with the DASH diet involves more than just the traditional low salt or low sodium diet advice. ${ }^{5}$ It is based on a dietary intake plan proven to lower BP, which is rich in fruits, vegetables, and low-fat or nonfat dairy. The plan emphasizes whole grains and contains less refined grains compared with a typical diet and is rich in potassium, magnesium, calcium, and fiber. ${ }^{5}$ Moreover, healthy lifestyles such as a reasonably balanced diet intake, undertaking regular physical exercise, and nonsmoking are among the most important preventive measures. ${ }^{6}$

Despite the availability of effective treatments, studies have shown that in many countries less than $25 \%$ of patients treated for HT achieve optimum BP. ${ }^{6}$ In a study conducted in $2015^{3}$ among treated hypertensive patients, the authors conclude that HT is prevalent in Lebanon and its overall control is low. ${ }^{3}$ Suboptimal or poor adherence has been identified as the main cause of failure to control HT. It also reduces the effectiveness of medications and has been highlighted as a significant obstacle in achieving the optimal clinical benefit. $^{7}$

The participants at the World Health Organization Adherence Meeting held in June 2001 adopted the following definition of adherence to long-term therapy: "The extent to which a person's behavior-taking medication, following a diet, and/or executing lifestyle changes, corresponds with agreed recommendations from a health care provider". 8

Although there is no golden standard for measuring adherence behavior, there are various methods for assessing adherence to medications. The most frequently used methods include patient self-report or questionnaire. ${ }^{9}$ The economic evaluation of non-adherence requires the recognition of the associated costs and outcomes. Non-adherence implies a cost due to the occurrence of the undesired effects that the suggested regimen tries to minimize. In terms of outcomes, nonadherence results in increased clinical risk and therefore in increased morbidity and mortality. ${ }^{10}$ Based on this, our study aims to evaluate the antihypertensive medication adherence in Lebanese hypertensive patients using a well-structured questionnaire and the factors predicting this behavior and to assess the extent of patient's knowledge and perceptions about the disease, risk factors, and medication side effects.

\section{Methods}

The cross-sectional study was conducted between May and September 2015 among a sample of 249 adults with HT. The participants were recruited randomly from patients visiting outpatient clinics located in hospitals, community and hospital pharmacies and from private cardiology clinics located in Baabda, in the Governorate of Mount Lebanon. Eligible participants were Lebanese adults diagnosed with primary (essential) HT treated with at least one antihypertensive medication. The study excluded patients with secondary HT, pregnant women, patients with a psychiatric illness or mental impairment, or patients unable to give informed consent. In addition, untreated hypertensive patients taking no medication and non-Lebanese subjects were also excluded.

The study protocol was reviewed and approved by the Institutional Review Board of Lebanese University. All participants were provided with clear and easy to understand information about the research project in order to allow them to make an informed and voluntary decision about whether or not to participate. In accordance with the privacy rule of the Health Insurance Portability and Accountability Act and the declaration of Helsinki, a written consent form was signed by each participant to indicate agreement to participate in this study. The data was collected by interviewers who had passed an exam offered by the National Institutes of Health office for extramural research related to the Protection of Human Research Participants. Standardized materials along with identical equipment were used by all trained interviewers. Telephone appointments were scheduled with cardiologists for the purpose of interviewing hypertensive patients.

A well-structured questionnaire was used to address the study objective. Information pertaining to demographic, education, lifestyle, medication and adherence, awareness, BP measurement, and family history of HT was collected for each subject.

$\mathrm{BP}$ readings were measured using an automated BP machine (Omron HEM-RML 31) while the participants were in the resting state for 8 minutes and in seated position. Height was measured to the nearest $0.1 \mathrm{~cm}$ with a non-stretchable measuring tape. Weight was measured to the nearest $0.1 \mathrm{~kg}$ with a digital scale (Omron HBF-500). Height and weight were measured with clothing on, but no shoes. Body mass index (in $\mathrm{kg} / \mathrm{m}^{2}$ ) was calculated based on height and weight readings.

The survey was conducted in Baabda south of Beirut where the population was estimated at 500,000 inhabitants. A minimum sample size of 249 participants is required to give a $95 \%$ confidence level with a confidence interval of $6.2 \%$. 
These data were entered and analyzed by Statistical Package for the Social Sciences program version 20. Qualitative data were represented in frequency and percentage, while quantitative data were represented as mean \pm standard deviation. Bivariate analysis of different variables with the adherence to medication was performed using the chi-square test. A value of $p<0.05$ was considered statistically significant. ${ }^{11}$

\section{Results}

\section{Sociodemographic characteristics}

Baseline demographic criteria of enrolled participants are reported in Table 1 . The mean age of participant was $62 \pm 17.2$ years. The study involved 129 (51.8\%) males and $120(48.2 \%)$ females with no significant age difference between males and females $(p=0.797)$. Randomly selected, 141 (56.6\%) participants were from pharmacies, 92 (37\%) from private cardiology clinics, and $16(6.4 \%)$ from hospitals. Survey respondents were predominantly married (214 [85.54\%]) and only $20.5 \%$ of the sample population

Table I Sociodemographic characteristics

\begin{tabular}{|c|c|}
\hline Variables & $\begin{array}{l}\text { Total participants, } \\
\mathrm{N}=249 \text { n (\%) }\end{array}$ \\
\hline Male sex & $129(5 \mid .8)$ \\
\hline Female sex & $120(48.2)$ \\
\hline \multicolumn{2}{|l|}{ Age (in years) } \\
\hline $26-45$ & $19(7.6)$ \\
\hline $46-65$ & $116(46.6)$ \\
\hline 66 or older & $114(45.8)$ \\
\hline \multicolumn{2}{|l|}{ Marital status } \\
\hline Single & $8(3.2)$ \\
\hline Married & $214(86.0)$ \\
\hline Divorced & I $(0.4)$ \\
\hline Widowed & $26(10.4)$ \\
\hline \multicolumn{2}{|l|}{ Education level } \\
\hline$<$ High school & $199(80.0)$ \\
\hline$>$ High school & $17(7.0)$ \\
\hline University & $13(5.0)$ \\
\hline Other & $20(8.0)$ \\
\hline \multicolumn{2}{|l|}{ Occupation } \\
\hline Not employed & $107(43.0)$ \\
\hline Employed & $49(19.6)$ \\
\hline Retired & 91 (36.6) \\
\hline Profession & I $(0.4)$ \\
\hline Student & I $(0.4)$ \\
\hline \multicolumn{2}{|l|}{ Location } \\
\hline Community pharmacy & $14 \mid(56.6)$ \\
\hline Clinic & $92(37.0)$ \\
\hline Hospital & $16(6.4)$ \\
\hline \multicolumn{2}{|l|}{ Physician specialty } \\
\hline Cardiologist & $243(97.6)$ \\
\hline General practitioner & $5(2.0)$ \\
\hline Other & I (0.4) \\
\hline
\end{tabular}

Note: The bold data indicate the highest percentage. were employed. Eighty percent of the participants did not reach high school (Table 1 ).

\section{$\mathrm{BP}$ and body dimensions}

The mean SBP was $138.95 \pm 18.35 \mathrm{mmHg}$ and DBP was $87.2 \pm 7.13 \mathrm{mmHg}$ showing an uncontrolled BP among participants.

The mean weight of participants was $80.94 \pm 14.95 \mathrm{~kg}$ and the mean height was $168.18 \pm 8.907 \mathrm{~cm}$. Overweight and obesity were declared in $42 \%$ and $35.3 \%$, respectively (Table 2).

\section{General health information and illness perception}

Among the participants analyzed, 37\% reported that they were first diagnosed with HT within the past 5 years. In addition, $84.7 \%$ of participants knew their BP reading when they were diagnosed with HT for the first time, and the SBP in $75 \%$ of them ranged between 160 and $200 \mathrm{mmHg}$. Knowledge of the underlying cause for the high BP was reported in $73 \%$ of the participants. It is revealing to know that $61 \%$ of the participants were hospitalized for uncontrolled BP. HT was accompanied with other cardiovascular comorbidities in $35.74 \%$ of cases, among which $20.5 \%$ appeared before being diagnosed with HT (Table 3).

\section{Medication information and adherence patterns}

Sixty-seven percent of the participants were on combination treatment for HT. The most widely prescribed type of antihypertensive medication was beta-blocker, which was used alone or in combination by $53 \%$ of the participants. It is noted that $48 \%$ of the participants declared changing their antihypertensive medications during the last year of

Table 2 Blood pressure and body dimensions

\begin{tabular}{ll}
\hline Body dimensions & Mean \pm SD \\
\hline Weight $(\mathrm{kg})$ & $80.94 \pm \mathrm{I} 4.95$ \\
Height $(\mathrm{cm})$ & $168.18 \pm 8.9 \mid$ \\
Systolic blood pressure $(\mathrm{mmHg})$ & $138.95 \pm \mid 8.35$ \\
Diastolic blood pressure $(\mathrm{mmHg})$ & $87.2 \pm 7.13$ \\
\hline Body mass index $\left(\mathrm{kg} / \mathrm{m}^{2}\right)$ & $\mathbf{n}(\%)$ \\
\hline$<18.5$ & $2(0.8)$ \\
$18.5-24.9$ & $54(21.7)$ \\
$25.0-29.9$ & $105(42.2)$ \\
$30.0-34.9$ & $58(23.3)$ \\
$35.0-39.9$ & $28(1 \mathrm{I} .2)$ \\
$\geq 40.0$ & $2(0.8)$ \\
\hline
\end{tabular}

Abbreviation: SD, standard deviation. 
Table 3 General health information and illness perceptions

\begin{tabular}{|c|c|}
\hline Variables & $\begin{array}{l}\text { Total participants, } \\
\mathbf{N}=\mathbf{2 4 9} \text { n (\%) }\end{array}$ \\
\hline \multicolumn{2}{|l|}{ Time of hypertension onset } \\
\hline Before 2005 & $102(4 \mid .0)$ \\
\hline $2005-2010$ & $55(22.0)$ \\
\hline $2011-2015$ & $92(37.0)$ \\
\hline pressure reading & $211(84.7)$ \\
\hline \multicolumn{2}{|l|}{$\begin{array}{l}\text { Initial blood pressure reading, specified } \\
\text { by patients }\end{array}$} \\
\hline $140-150 \mathrm{mmHg}$ & $23(11.0)$ \\
\hline $160-200 \mathrm{mmHg}$ & $158(75.0)$ \\
\hline$>200 \mathrm{mmHg}$ & $30(14.0)$ \\
\hline $\begin{array}{l}\text { Patients who understand the } \\
\text { underlying cause }\end{array}$ & $182(73.0)$ \\
\hline $\begin{array}{l}\text { Emergency room visits or } \\
\text { hospitalization for high blood pressure }\end{array}$ & $152(6 \mid .0)$ \\
\hline Presence of concomitant diseases & $89(35.7)$ \\
\hline \multicolumn{2}{|l|}{ If yes, } \\
\hline After being diagnosed with hypertension & 71 (79.5) \\
\hline Before being diagnosed with hypertension & $18(20.5)$ \\
\hline \multicolumn{2}{|l|}{ Patient interest or health goals to aging well } \\
\hline Reducing stress & $200(80.3)$ \\
\hline Losing weight & $23(9.2)$ \\
\hline Eating better & $15(6)$ \\
\hline Exercising & II (4.5) \\
\hline
\end{tabular}

Note: The bold data indicate the highest percentage.

treatment for uncontrolled BP and for non-tolerated side effects in $53 \%$ and $41 \%$ of the cases, respectively. Surprisingly, only $11.6 \%$ of participants were self-medicated mainly with non-steroidal anti-inflammatory drugs. Regarding the alternative HT treatment, $68 \%$ of the participants were supplement users. Among this group, $42 \%$ used OMEGA-3, co-Q10, and vitamin D for controlling HT, and 37\% used DASH diet, which is considered as a new supplement food type. However, physical activities were reported by only $11 \%$ of participants.

With regard to adherence, $85 \%$ of the participants were taking their antihypertensive medications as prescribed by their doctors. Thirty-seven (15\%) participants did not adhere to the prescribed medications. Among these participants, 33 (89.2\%) related non-adherence to mere forgetfulness (Table 4).

\section{BP information and awareness}

More than half of the participants (52.6\%) reported visiting their physicians for regular checkups, and $28 \%$ visited their doctors every 3-6 months for follow-up. As recommended by their physicians, $72 \%$ checked their BP at home. The last BP readings ranged between 150 and $180 \mathrm{mmHg}$ in $35 \%$ of participants, which is considered high, and $48.6 \%$ of the participants stated that their last BP reading was done
Table 4 Medication information and adherence patterns

\begin{tabular}{|c|c|}
\hline Variables & $\begin{array}{l}\text { Total participants, } \\
\mathrm{N}=249 \text { n (\%) }\end{array}$ \\
\hline \multicolumn{2}{|c|}{ Pharmacological category of antihypertensive medication } \\
\hline Combination drug & $167(67.1)$ \\
\hline Beta-blockers & $31(12.5)$ \\
\hline Calcium channel blockers & $25(10.0)$ \\
\hline $\begin{array}{l}\text { Angiotensin-converting enzyme inhibitor/ } \\
\text { angiotensin II-receptor blocker }\end{array}$ & $24(9.6)$ \\
\hline Diuretics & $2(0.8)$ \\
\hline Patients being currently treated & $130(52.0)$ \\
\hline \multicolumn{2}{|l|}{ If treatment was modified, give the reason } \\
\hline Uncontrolled hypertension & $63(53.0)$ \\
\hline Drug was not tolerated & $49(41.0)$ \\
\hline Other reasons & $7(6.0)$ \\
\hline $\begin{array}{l}\text { Self-medicating patients with non-prescription } \\
\text { medications }\end{array}$ & $29(11.6)$ \\
\hline \multicolumn{2}{|l|}{ If yes, class of non-prescription medications } \\
\hline Non-steroid anti-inflammatory drugs & $26(89.6)$ \\
\hline Decongestants & $2(6.9)$ \\
\hline Contraceptive drugs & I (3.5) \\
\hline $\begin{array}{l}\text { Use of supplements or alternatives to treat } \\
\text { hypertension }\end{array}$ & $169(68.0)$ \\
\hline \multicolumn{2}{|l|}{ If yes, } \\
\hline Supplements (omega 3, vitamin D, ginkgo, etc.) & $71(42.0)$ \\
\hline Dietary approaches to stop hypertension diet & $63(37.3)$ \\
\hline Physical activities & $18(10.7)$ \\
\hline Food supplements & $17(10.0)$ \\
\hline Patients adhering to physician's prescription & $212(85.0)$ \\
\hline \multicolumn{2}{|l|}{ If not, reason for non-adherence } \\
\hline Simple forgetfulness & $33(89.2)$ \\
\hline Side effects & $2(5.4)$ \\
\hline High medication cost & $\mathrm{I}(2.7)$ \\
\hline Do not need it/do not think about it & I (2.7) \\
\hline
\end{tabular}

Note: The bold data indicate the highest percentage.

2 weeks earlier. In addition, $41.4 \%$ of participants claimed to have occasional headaches as a symptom of uncontrolled BP. The study also showed that $97 \%$ of the participants were aware that non-compliance may affect their health status. However, $96.4 \%$ of the study group did not use a special container for medication packaging, and $98 \%$ did not receive a reminder from their physician or pharmacist to refill their prescription (Table 5).

\section{Factors associated with medication adherence}

Two hundred thirty-three (93.5\%) participants who adhered to the prescribed medications were covered by health insurance, which shows a significant association $(p=0.01)$, between health coverage and adherence. In addition, $97.6 \%$ of participants visit cardiologist ( $p=0.807$ ), $84.7 \%$ of them knew the reading of their BP when diagnosed with HT for the first time ( $p=0.093$ ), $73.1 \%$ admitted that they knew the underlying cause of their disease $(p=0.645), 72 \%$ 
Table 5 Awareness, blood pressure information, and relationship with healthcare provider

\begin{tabular}{|c|c|}
\hline Variables & $\begin{array}{l}\text { Total participants, } \\
\mathrm{N}=\mathbf{2 4 9} \text { n (\%) }\end{array}$ \\
\hline \multicolumn{2}{|l|}{ Frequency of physician visit } \\
\hline No regular checkups & |3| (52.6) \\
\hline Monthly & $24(9.6)$ \\
\hline Every $3-6$ months & $70(28.1)$ \\
\hline Once a year & $24(9.6)$ \\
\hline \multicolumn{2}{|l|}{ Refilling medication after the initial prescription } \\
\hline Self-refill & $155(62.0)$ \\
\hline Recontacting the physician & $42(17.0)$ \\
\hline $\begin{array}{l}\text { Patients told by physician to check their } \\
\text { blood pressure at home }\end{array}$ & $209(84.0)$ \\
\hline $\begin{array}{l}\text { Patients who measure their blood pressure } \\
\text { at home }\end{array}$ & $179(72.0)$ \\
\hline \multicolumn{2}{|l|}{ Time of last reading } \\
\hline Same day/I day earlier & $42(16.9)$ \\
\hline Within the study week & $52(20.9)$ \\
\hline Two weeks prior to study & $121(48.6)$ \\
\hline Over 2 weeks prior to the study & $34(13.6)$ \\
\hline \multicolumn{2}{|c|}{ Last blood pressure reading (systolic/diastolic blood pressure) } \\
\hline$<100 \mathrm{mmHg} /<80 \mathrm{mmHg}$ & $15(6.0)$ \\
\hline $120 / 80 \mathrm{mmHg}$ & $147(59.0)$ \\
\hline $160 / 100 \mathrm{mmHg}$ & $76(30.5)$ \\
\hline$>160 \mathrm{mmHg}>100 \mathrm{mmHg}$ & II (4.5) \\
\hline \multicolumn{2}{|l|}{ Symptoms caused by uncontrolled blood pressure } \\
\hline Headaches & $103(41.4)$ \\
\hline Dizziness & $37(14.9)$ \\
\hline Blurry vision & $29(11.6)$ \\
\hline Chest pain & $25(10.0)$ \\
\hline None & $21(8.5)$ \\
\hline Other & $34(13.6)$ \\
\hline $\begin{array}{l}\text { Patients who had their cholesterol levels } \\
\text { checked }\end{array}$ & $147(59.0)$ \\
\hline \multicolumn{2}{|l|}{ If yes, low-density lipoprotein measurement } \\
\hline $100-120 \mathrm{mg} / \mathrm{dL}$ & $7(4.8)$ \\
\hline $130-159 \mathrm{mg} / \mathrm{dL}$ & $15(10.2)$ \\
\hline$\geq 160 \mathrm{mg} / \mathrm{dL}$ & $35(23.8)$ \\
\hline Unknown & $90(61.2)$ \\
\hline $\begin{array}{l}\text { Patients educated by physician about risks of } \\
\text { non-adherence }\end{array}$ & $130(52.2)$ \\
\hline \multicolumn{2}{|c|}{$\begin{array}{l}\text { Patients' opinion on the effect of non-compliance to medication on } \\
\text { health status }\end{array}$} \\
\hline Risk of associated health effects & $242(97.0)$ \\
\hline No risk of associated health effects & $5(2.0)$ \\
\hline Possibility of health effect risk/do not know & $2(1.0)$ \\
\hline $\begin{array}{l}\text { Use of special containers for medication } \\
\text { packaging (pill, box, blister pack, etc.) }\end{array}$ & $9(3.6)$ \\
\hline $\begin{array}{l}\text { Patients who receive prescription refill } \\
\text { reminders from physician or pharmacist }\end{array}$ & $5(2.0)$ \\
\hline
\end{tabular}

Note: The bold data indicate the highest percentage.

measure their BP at home $(p=0.205), 68 \%$ take supplements for HT treatment $(p=0.746), 80 \%$ were hospitalized for high BP $(p=0.168)$. All these findings show no significant difference between adherent and non-adherent participants (Table 6).
Table 6 Variables associated with medication adherence

\begin{tabular}{|c|c|c|}
\hline Variables & $\begin{array}{l}\text { Total participants, } \\
\mathbf{N}=249 \text { n (\%) }\end{array}$ & $p$-value \\
\hline Cardiologist & $243(97.6)$ & 0.807 \\
\hline Health insurance & $233(93.6)$ & $0.01 *$ \\
\hline $\begin{array}{l}\text { Knowledge of the patient about blood } \\
\text { pressure reading }\end{array}$ & $211(84.7)$ & 0.093 \\
\hline Understanding of underlying cause & $182(73.1)$ & 0.645 \\
\hline Blood pressure measured at home & $179(72.0)$ & 0.205 \\
\hline $\begin{array}{l}\text { Supplements or alternatives for } \\
\text { hypertension treatment }\end{array}$ & $169(68.0)$ & 0.746 \\
\hline Hospitalization for high blood pressure & $152(6 \mid .0)$ & 0.168 \\
\hline
\end{tabular}

\section{Discussion}

When BP is too high for too long, it damages the blood vessels and low-density lipoprotein cholesterol begins to accumulate along tears in the artery walls. This increases the workload of the circulatory system while decreasing its efficiency. As a result, high BP puts the patient at greater risk for the development of life-changing and potentially life-threating conditions. ${ }^{12}$ The study was carried out to examine the prevalence of adherence to antihypertensive treatment and the extent of patient's knowledge about the disease, risk factors, and medication side effects. Stress, limited physical activity, and unhealthy diet emerged as the perceived most important risk factors of HT. The study also demonstrates that $85 \%$ of the participants were found to be adherent to their treatment. This percentage is greater than the rate of adherence $(77.6 \%)$ in a study conducted in Beirut in 2015, ${ }^{13}$ and reported from Germany (56\%), ${ }^{14}$ Ethiopia (64.6\%), ${ }^{15}$ Saudi Arabia (53\%), ${ }^{10}$ China (65.1\%), ${ }^{16}$ Malaysia (44.2\%), ${ }^{17}$ Pakistan (57\%), ${ }^{18}$ and Gambia 27\% ${ }^{19}$ However, this percentage is lower than that demonstrated by a study conducted in Scotland (91\%). ${ }^{20}$ The percentage of $85 \%$ seems to be biased as participants were unaware about the exact definition of adherence, despite the efforts made by the trained interviewers. The results could be explained by the low educational level observed in $80 \%$ of the participants. The results are also supported by the following findings: $52.6 \%$ of the participants did not follow regular checkups with their healthcare providers; $48.6 \%$ did not check their BP for more than 2 weeks; $41.4 \%$ suffered from headache due to uncontrolled BP; and 61\% were hospitalized for uncontrolled BP. In addition, 93.5\% of the study group, which showed a significance association with adherence, had a health coverage that eliminated the cost factor, which is considered as one of the most common barriers to medication adherence. Consequently, as hospitalization is costly in developing countries suffering from limited resources, 
healthcare providers and payers should focus on interventions to improve medication adherence. The Ministry of Public Health in Lebanon covers hospital inpatient expenditures of uninsured patients, which are estimated to be half of the Lebanese population. Medication adherence is a growing concern to clinicians, healthcare systems, and other stakeholders (eg, payers) in the majority of countries. Such concern is due to the mounting evidence that non-adherence is prevalent and is associated with adverse outcomes and higher costs of care. ${ }^{21}$ These findings emphasize the importance of raising awareness and promoting the knowledge about adherence definition and behavior to hypertensive patients.

The results of our study show that there is no significant association between HT knowledge and medication adherence as reported by $85 \%$ of the participants. These results are consistent with a study performed in patients recruited from a health maintenance organization in United States, which showed no significant effects between compliance to medications and the knowledge regarding HT. Our study also showed that $73.1 \%$ of the participants knew the underlying cause of the disease and that no significant difference was demonstrated between adherence and non-adherence, although learning about HT and its underlying causes may be helpful in improving adherence. ${ }^{22}$

The Nigerian's study shows that patients attending the cardiology clinic had at least a higher level of medium medication adherence than those attending general outpatient clinic. ${ }^{23}$ In our study, there was no significant difference between physician specialty and medication adherence. This can be explained by the confidence and satisfaction perceived by patients choosing to visit either generalist or specialized physician.

A Japanese questionnaire-based study ${ }^{24}$ found that $49 \%$ of patients reported adverse effects with their antihypertensive medicines, and a statistically significant relationship between the number of reported adverse effects and nonadherence. These results are consistent with our study, which demonstrates that $41 \%$ of participants had changed their antihypertensive medications during the last year because of medication non-tolerated side effects. Physicians should tell the patients about the adverse effects of the prescribed drugs and the risk of rebound effect related to antihypertensive drugs' abrupt discontinuation.

Poor memory was the most commonly reported barrier to medication adherence as $89.5 \%$ of non-adherent participants in our study referred their practice to mere forgetfulness. This finding is in line with that of a study from Pakistan, which reported that $56.8 \%$ of the participants missed doses due to forgetfulness. ${ }^{25}$ Moreover, our data demonstrate that only $3.6 \%$ of the treating physicians recommend the use of special container for medication packaging, and that $2 \%$ of the pharmacists or physicians remind their patients to refill their prescription. Appropriate measures should be taken to enhance patient memory, including planning to take medications in conjunction with certain activities, such as eating meals, and recommending the use of pill boxes that organize the process of medication intake.

A substantial portion of patients with HT in our study (42\%) used complementary and alternative medicine (CAM) in addition to prescribed medications to help control their BP, compared to $26.5 \%$ in a study conducted in Louisiana. ${ }^{26}$ Based on this, it can be said that the use of CAM may be an important modifiable barrier or a signal of other barriers (eg, side effects and costs of medications) to antihypertensive medication adherence and subsequent BP control.

In addition, our study shows that $37 \%$ of the participants are following a DASH diet, which reflects an aspect of a management plan that adherers complied with, in addition to taking medication. A study conducted in the United States shows that compared with the control diet of high sodium level, the DASH diet with a low sodium level led to a mean SBP that was $11.5 \mathrm{mmHg}$ lower in participants with HT. ${ }^{27}$ Another study shows that BP in the DASH group fell from $146 / 85$ to $134 / 82 \mathrm{mmHg}{ }^{28}$ This probably indicates that HT management is an integrated plan where the pharmacological treatment is complementary to the non-pharmacological one.

In our study, $41 \%$ of participants presented with HT for more than 10 years. Our finding is consistent with a study conducted in Nigeria, which found that the duration of HT was the highest (11.4 years) in the high adherence group. ${ }^{29}$ Similarly, a study conducted in China ${ }^{14}$ shows that patients with longer duration of antihypertensive agents used over 10 years reported better adherence than patients with shorter duration of 5 years or less. Based on such findings, it may be concluded that a history of HT can be related to adherence level. In fact, these participants are likely to have more information about the disease and established stronger patient-physician relationship than those with a shorter history of HT.

The interaction with participants completing the questionnaire survey revealed that the majority considered the relationship with their physician to be of great importance. It was demonstrated that $48 \%$ of the participants did not get the necessary counseling on the risk of non-adherence from their health care providers. Interestingly, the study of Degli Esposti et al shows that younger doctors tended to have more adherent patients. ${ }^{30}$ Ren et al have also found that patients treated by nurses or physicians' assistants were more likely to be compliant than patients treated by physicians. ${ }^{31}$ Distant and formal 
physician-patient relationship could compel the patient to go to another treating physician and lead to non-adherence.

\section{Conclusion}

This study presents important findings about the need for more informed knowledge about the disease, risk factors, and medication side effects in order to enhance adherence to treatment. The study also highlights many factors that may impact adherence levels, and confirms the importance of cognitive and communication status.

We therefore conclude that chronic disorders such as HT can be better managed if it is provided together with the provision of qualitative health education aimed at improving medication adherence at the community level, reducing the worldwide burden of cardiovascular disease associated with HT, and reducing healthcare cost in specific.

\section{Acknowledgment}

This project has been funded with support from Lebanese University.

\section{Disclosure}

The authors report no conflicts of interest in this work.

\section{References}

1. Global Health Observatory (GHO) data. Raised blood pressure: situation and trends. World Health Organization. 2014. Available from: http:// www.who.int/gho/ncd/risk_factors/blood_pressure_prevalence_text/ en/. Accessed January 10, 2017.

2. Matar D, Frangieh AH, Abouassi S, et al. Prevalence, awareness, treatment, and control of hypertension in Lebanon. J Clin Hypertens (Greenwich). 2015;17(5):381-388.

3. Tohme RA, Jurjus AR, Estephan A. The prevalence of hypertension and its association with other cardiovascular disease risk factors in a representative sample of the Lebanese population. J Hum Hypertens. 2005;19(11):861-868.

4. Joint National Committee 8 ( $\mathrm{JNC} 8$ ) guidelines for the management of hypertension in adults. Am Fam Physician. 2014;90(7):503-504.

5. National Heart, Lung, and Blood Institute (NHLBI). DASH Eating Plan. 2014. Available from: https://www.nhlbi.nih.gov/health/health-topics/ topics/dash. Accessed December 10, 2016.

6. Sulbaran T, Silva E, Calmon G, Vegas A. Epidemiologic aspects of arterial hypertension in Maracaibo, Venezuela. J Hum Hypertens. 2000;14(Suppl 1):S6-S9.

7. World Health Organization. Adherence to long-term therapies: evidence for action. Geneva: World Health Organization; 2003. Available from: http://www.who.int/chp/knowledge/publications/ adherence_introduction.pdf. Accessed December 10, 2016.

8. World Health Organisation. Cardiovascular diseases (CVDs). Fact sheet [updated May 2017]. Available from: http://www.who.int/mediacentre/ factsheets/fs317/en/. Accessed May 18, 2016.

9. ABC Project. Ascertaining barriers for compliance: policies for safe, effective and cost-effective use of medicines in Europe. ABC Project. 2012. Available from: http://www.abcproject.eu/img/ABC\%20 FINAL.pdf. Accessed January 10, 2017.

10. Khalil SA, Elzubier AG. Drug compliance among hypertensive patients in Tabuk, Saudi Arabia. J Hypertens. 1997;15(5):561-565.
11. Surveysystem.com. Creative Research Systems. 2012. Available from: http://www.surveysystem.com/sscalc.htm

12. AHA High Blood Pressure Web. Updated May 2017. Available from: http://www.heart.org/HEARTORG/Conditions/HighBloodPressure/ LearnHowHBPHarmsYourHealth/Health-Threats-From-High-Blood Pressure_UCM_002051_Article.jsp\#.WdN5xPVrzDc

13. Yassine M, Al Hajj A, Awada S, et al. Evaluation of medication adherence in Lebanese hypertensive patients. J Epidemiol Glob Health. 2016; 6(3):157-167.

14. Schmieder RE, Ott C, Schmid A, et al. Adherence to antihypertensive medication in treatment-resistant hypertension undergoing renal denervation. $J$ Am Heart Assoc. 2016;5(2):e002343.

15. Ambaw AD, Alemie GA, W/Yohannes SM, Mengesha ZB. Adherence to antihypertensive treatment and associated factors among patients on follow up at University of Gondar Hospital, Northwest Ethiopia. BMC Public Health. 2012;12(2):282.

16. Lee GK, Wang HH, Liu KQ, Cheung Y, Morisky DE, Wong MC. Determinants of medication adherence to antihypertensive medications among a Chinese population using Morisky Medication Adherence Scale. PLoS One. 2013;8(4):e62775.

17. Morisky DE, Green LW, Levine DM. Concurrent and predictive validity of a self-reported measure of medication adherence. Med Care. 1986;24(1):67-74.

18. Lennon C, Hughes CM, Johnston GD, McElnay JC. Identification of psychosocial factors which influence patient adherence with antihypertensive medication. Int J Pharm Pract. 2001;9(Suppl 1):R8.

19. van der Sande MA, Milligan PJ, Nyan OA, et al. Blood pressure patterns and cardiovascular risk factors in rural and urban Gambian communities. J Hum Hypertens. 2000;14(8):489-496.

20. Youssef RM, Moubarak II. Patterns and determinants of treatment compliance among hypertensive patients. East Mediterr Health J. 2002; 8(4-5):579-592.

21. Ammar W. Health beyond politics. World Health Organization Eastern Mediterranean Regional Office. Lebanon: Ministry of Public Health; 2009.

22. Wang PS, Bohn RL, Knight E, Glynn RJ, Mogun H, Avorn J. Noncompliance with antihypertensive medications: the impact of depressive symptoms and psychosocial factors. J Gen Intern Med. 2002;17(7):504-511.

23. Akintunde AA, Akintunde TS. Antihypertensive medications adherence among Nigerian hypertensive subjects in a specialist clinic compared to a general outpatient clinic. Ann Med Health Sci Res. 2015; 5(3):173-178.

24. Toyoshima H, Takahashi K, Akera T. The impact of side effects on hypertension management: a Japanese survey. Clin Ther. 1997;19(6): $1458-1469$.

25. Almas A, Hameed A, Ahmed B, Islam M. Compliance to anti-hypertensive therapy. J Coll Physicians Surg Pak. 2006;16(1):23-26.

26. Krousel-Wood MA, Muntner P, Joyce CJ, et al. Adverse effects of complementary and alternative medicine use on antihypertensive medication adherence: findings from the cohort study of medication adherence among older adults. J Am Geriatr Soc. 2010;58(1):54-61.

27. Sacks FM, Svetkey LP, Vollmer WM, et al; DASH-Sodium Collaborative Research Group. Effects on blood pressure of reduced dietary sodium and the dietary approaches to stop hypertension (DASH) diet. N Engl J Med. 2001;344(1):3-10.

28. Moore TJ, Conlin PR, Ard J, Svetkey LP. DASH (dietary approaches to stop hypertension) diet is effective treatment for stage 1 isolated systolic hypertension. Hypertension. 2001;38(2):155-158.

29. Hyre AD, Krousel-Wood MA, Muntner P, Kawasaki L, DeSalvo KB. Prevalence and predictors of poor antihypertensive medication adherence in an urban health clinic setting. J Clin Hypertens (Greenwich). 2007;9(3):179-186.

30. Degli Esposti E, Sturani A, Di Martino M, et al. Long-term persistence with antihypertensive drugs in new patients. J Hum Hypertens. 2002;16(6):439-444.

31. Ren XS, Kazis LE, Lee A, Zhang H, Miller DR. Identifying patient and physician characteristics that affect compliance with antihypertensive medications. J Clin Pharm Ther. 2002;27(1):47-56. 


\section{Publish your work in this journal}

Patient Preference and Adherence is an international, peer-reviewed, open access journal that focuses on the growing importance of patient preference and adherence throughout the therapeutic continuum. Patient satisfaction, acceptability, quality of life, compliance, persistence and their role in developing new therapeutic modalities and compounds to optimize

clinical outcomes for existing disease states are major areas of interest for the journal. This journal has been accepted for indexing on PubMed Central. The manuscript management system is completely online and includes a very quick and fair peer-review system, which is all easy to use. Visit http://www. dovepress.com/testimonials.php to read real quotes from published authors.

Submit your manuscript here: http://www.dovepress.com/patient-preference-and-adherence-journal 